(C) 2022, The Authors. Published by Elsevier Inc. and Fass Inc. on behalf of the American Dairy Science Association ${ }^{\circledR}$. This is an open access article under the CC BY license (http://creativecommons.org/licenses/by/4.0/).

\title{
Preferences of European dairy stakeholders in breeding for resilient and efficient cattle: A best-worst scaling approach
}

\author{
J. G. Burns, ${ }^{1,2 *} \odot$ K. Glenk, ${ }^{2} \odot$ V. Eory, ${ }^{2} \odot$ G. Simm, ${ }^{1} \oplus$ and E. Wall ${ }^{2} \odot$ \\ ${ }^{1}$ Global Academy of Agriculture and Food Security, University of Edinburgh, Easter Bush Campus, Edinburgh, EH25 9RG, United Kingdom \\ ${ }^{2}$ Scotland's Rural College (SRUC), Peter Wilson Building, King's Buildings, Edinburgh, EH9 3JG, United Kingdom
}

\begin{abstract}
Including resilience in the breeding objective of dairy cattle is gaining increasing attention, primarily as anticipated challenges to production systems, such as climate change, may make some perturbations more difficult to moderate at the farm level. Consequently, the underlying biological mechanisms by which resilience is achieved are likely to become an important part of the system itself, increasing value on the animal's ability to be unperturbed by variable production circumstances, or to quickly return to pre-perturbed levels of productivity and health. However, because the value of improving genetic traits to a system is usually based on known profit functions or bioeconomic models linked to current production conditions, it can be difficult to define longer-term value, especially under uncertain future production circumstances and where nonmonetary values may be progressively more important. We present the novel application of a discrete choice experiment, used to investigate potential antagonisms in the values of genetic improvements for 8 traits to dairy cattle system stakeholders in Europe when the production goal was either efficiency or resilience. A latent class model was used to identify heterogeneous preferences within each production goal, and postestimation was used to identify associations between these preferences and sociodemographic characteristics of respondents. Results suggested 3 distinct latent preference classes for each production goal. For the efficiency goal, yield and feed efficiency traits were generally highly valued, whereas for the resilience goal, health and robustness traits were generally highly valued. In both cases, these traits generally carried a low value in the other production scenario. Overall, in both scenarios, longevity was highly valued; however, the value of this trait in terms of resilience will depend on phenotyping across diverse environments to sufficiently capture performance under
\end{abstract}

Received February 16, 2021.

Accepted October 16, 2021.

*Corresponding author: jay.burns@sruc.ac.uk various anticipated system challenges. Additionally, results showed significant associations between membership of latent preference classes with education level and profession. In conclusion, as resilience becomes increasingly important, it is likely that a continued reliance on the short-term economic value of traits alone will lead decision makers to misrepresent the importance of some traits, including those with substantial contextual values in terms of resilience.

Key words: trait preference, breeding objective, resilient cattle, dairy selection index, discrete choice experiment

\section{INTRODUCTION}

In highly productive European dairy cattle systems, managing perturbations generally follows a maximum control paradigm, in which farmers and industry stakeholders seek to minimize the effect of production challenges on individuals in the herd by highly regulating the management of feed, housing, and disease (ten Napel et al., 2011; Tixier-Boichard et al., 2015; Friggens et al., 2017). In this case, objective functions of production, such as milk yield, are maximized partly by shielding individuals from external stressors. In these highly controlled production systems, there is no benefit to promoting individuals who are unperturbed by external stressors. However, continuing changes in production circumstances are now expected, including climate-related instability (Kovats et al., 2014; EEA, 2017). This is likely to affect cattle productivity via multiple direct and indirect pathways (Kipling et al., 2019, 2016), with direct effects that include known health and productivity losses across environmental gradients (Strandberg et al., 2009; Rauw and GomezRaya, 2015), and indirect effects that include changes to the availability and production of forage and feed crops (Dellar et al., 2018). With authoritative projections predicting the continued increase in frequency and duration of extreme weather perturbations, which are supported by recently observed trends, resilience is now considered a key factor that will shape the future 
severity of such impacts on food production (Walker et al., 2004; Darnhofer, 2014; Bullock et al., 2017).

Resilience can be considered as the ability of a system to cope with challenges via mechanisms underlined by robustness, adaptability, and transformability (Meuwissen et al., 2019). However, at the individual animal level, it is common to focus more on mechanisms of robustness and adaptability, which we do herein (ten Napel et al., 2011; Ge et al., 2016). When compared with the maximum control paradigm, which has eroded the ability of highly efficient individuals to maintain efficiency under suboptimal production circumstances (Hill and Wall, 2015, 2017), the resilience paradigm seeks to promote the underlying biological characteristics that enable individuals to maintain efficiency levels (Figure 1), even when production circumstances are suboptimal (Friggens et al., 2017). Requirements to maintain efficiency are 2-fold: individuals must be minimally affected by perturbations, or, if affected, they must quickly return to their normal level of functioning (Colditz and Hine, 2016). Hence, a system following the resilience paradigm would accept a reduced capacity to shield individuals from external stressors, instead bestowing a greater reliance on the individual's ability to cope with variability in their production environment. Given projections of - and uncertainties around - future production circumstances, it is highly likely that the value of resilience is nonzero (Berghof et al., 2019); therefore, it should be fostered at the animal level by inclusion into the breeding objective. In this way, genetic improvement may be balanced not only for production and functional traits, as is the norm (Miglior et al., 2017, 2005), but also for resilience traits (Colditz and Hine, 2016; Friggens et al., 2017; Berghof et al., 2019; Poppe et al., 2020).

In genetic improvement programs, individuals are considered as a collection of genetic traits, and improvement is usually directed by the monetary value of traits from the perspective of commercial farmers (Brascamp et al., 1985). As such, with breeding decisions, profit is maximized, and choices are simplified as candidates are described according to a single value that represents the sum of their performance across a set of measur- able traits in a breeding objective (Groen, 1989). Although research is already underway to identify traits that will be important for the resilience of future cows, such as reducing variation in daily yields (Elgersma et al., 2018; Poppe et al., 2020), the definition of a monetary value for resilience in a breeding objective may be more problematic for 2 notable reasons. First, using contemporary approaches, the value of traits must be deterministic and usually linked to short-term markets (Simm, 1998), whereas the value of resilience traits may be dynamic and dependent on uncertain future production circumstances (Friggens et al., 2017). Second, some of the value may not be well transferred via the market; for example, resilience may deliver cobenefits to social and environmental targets, the value of which can be difficult to capture in monetary terms, regardless of relevance in the decision-making process (Nielsen et al., 2008; Bos et al., 2018; Busch and Spiller, 2018). Resultantly, some traits may be undervalued by conventional methods.

In situations where the derivation of value for traits is less clear, there are preference-based approaches to derive value under actual or theoretical production circumstances. Such preference-based approaches can be used to give an indication of the direction of genetic improvement desired by stakeholders, without limiting the value of an improvement to market value alone (Sae-Lim et al., 2012). There are numerous applications of such methods to date, some of which are detailed by Nielsen et al. (2014), and some have even influenced national agricultural genetic strategies (Byrne et al., 2016; Bos et al., 2018). Such methods are still consistent with the philosophy and formulation of breeding objectives, with which an individual's merit is expressed as a product of their performance across a set of valued traits. Thus far, these methods have largely been used either to capture conventional value where data availability is problematic (Chawala et al., 2019), to evaluate nonmarket trait values (Nielsen et al., 2006), or to explore heterogeneity in trait preferences between stakeholders (Martin-Collado et al., 2015). However, preference-based approaches also offer opportunities to investigate trade-offs and synergies in the value of

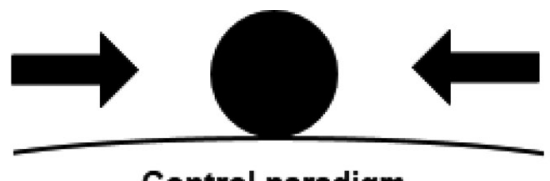

Control paradigm

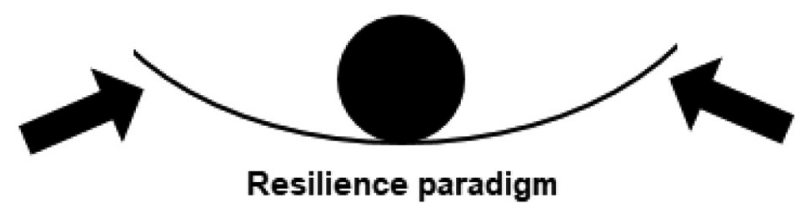

Figure 1. Visual representations of the control and resilience paradigms. Here, the lines can be considered to represent the individual, the arrows signify effort exerted by the farm, and the balls are the output of the individual. Under the control paradigm, farm effort is applied directly toward maintaining the individual's output. Under the resilience paradigm, farm effort is used to ensure individuals can moderate their own outputs (adapted from Holling, 1973; ten Napel et al., 2011). 
traits between competing breeding goals, particularly when looking to the longer-term when production and market circumstances are uncertain.

Despite growing interest in the inclusion of resilience traits into breeding objectives (Colditz and Hine, 2016; Friggens et al., 2017; Berghof et al., 2019; Poppe et al., 2020), and despite the increasing use of preference-based approaches in the evaluation of breeding objectives (Martin-Collado et al., 2015; Byrne et al., 2016), applications of a preference-based approach to explore trade-offs between genetic traits under different production objectives are scarce (Slagboom et al., 2016). We addressed this knowledge gap by applying a preference-based approach to stakeholders of dairy cattle production systems to understand how the relative importance of traits changes depending on if efficiency or resilience is the production goal. In this paper, we also described the first application of the best-worst scaling preference-elicitation method in this context (see Materials and Methods). We presented and discussed discrete preference structures that indicate key trade-offs between traits important for efficient or resilient production (see Results and Discussion sections). In addition, we explored how sociodemographic characteristics of respondents may explain variation in preferences (see Results and Discussion).

\section{MATERIALS AND METHODS}

\section{Best-Worst Scaling}

Best-worst scaling (BWS) is a form of discrete choice experiment; in this article, BWS specifically refers to object-case BWS (as opposed to profile-case or multiprofile-case BWS; Louviere et al., 2015). With BWS, respondents are presented with a series of choice sets, each containing a subset of all the items to be evaluated. Here, items were the genetic traits of dairy cattle, the selection of which would lead to a defined improvement in the performance of subsequent generations. For each choice set, respondents were required to select the best and worst trait on an underlying latent subjective utility scale (Lancaster, 1966). In the present case, the utility continuum can be interpreted as the relative effect of improving a trait to a farm system. Of course, respondents are assumed to have a utility for all traits. However, as choice sets followed an experimental design (see Experimental Design section below), respondents only needed to indicate those items at the extremes of the utility continuum, from which it is possible to infer the relative utility of all items across all choice sets (Aizaki et al., 2014).

In this context, the BWS framework is consistent with real-life trade-offs inherent in breeding decisions for dairy cattle, where animals are selected according to their relative performance in a set of genetic traits and decision makers must balance the relative importance of genetic traits appropriately for their production circumstances (Simm, 1998; Miglior et al., 2017), albeit often with input from breeding companies (Ooi et al., 2021). To ascertain how the relative importance of traits is affected by the production circumstances, respondents were required to make the same series of choices in the context of 2 separate production goals: resilience and efficiency.

\section{Experimental Design, Survey Construction, and Dissemination}

Traits were selected partially based on the results of an earlier questionnaire, which asked 25 partners and stakeholders of the multidisciplinary, multicountry Horizon-2020 GenTORE project ("GEnomic management Tools to Optimise Resilience and Efficiency" pertaining to European cattle production) to identify traits important to a resilient or efficient production goal in an open format. Across both goals, the most cited traits were those relating to yield, health, feed efficiency, adaptability, longevity, fertility, and reproduction; important novel traits included methane emissions and traits related to production efficiencies and early disease detection. In total, 8 traits were selected for inclusion in the discrete choice experiment. These were balanced not only based on the aforementioned results, but also to constitute a representative selection index (Miglior et al., 2005; 2017) and, importantly, to be easily understandable in terms of practical production benefits.

Respondents were presented with 14 choice sets, each of which contained a subset of 4 traits out of a total of 8. The appearance of traits within choice sets followed a balanced incomplete block design, constructed using the $\mathrm{R}$ packages crossdes (Sailer, 2013) and support. $B W S$ (Aizaki, 2020). An example choice set can be seen in Figure 2. The traits were described in terms of (1) the general trait group, (2) the specific trait, and (3) the response to selection that would be achievable if all selection emphasis was on that single trait, ignoring correlated effects (more details in Response to Selection section). Below each choice set, respondents were also provided a more detailed description of the featured traits. These descriptions can be found in Table 1. Before completing the choice tasks, respondents were given information on the purpose of the study, the meanings of resilience and efficiency (specifically in the context of production challenges), and how to complete the choice tasks. The survey also included questions concerning respondent characteristics and attitudes to 


\begin{tabular}{ccccc}
\hline \multicolumn{2}{c}{ Efficiency } & Trait & \multicolumn{2}{c}{ Resilience } \\
Best & Worst & Best & Worst \\
$\square$ & $\square$ & Production: Protein yield (+3.3 & $\square$ & $\square$ \\
$\square$ & $\square$ & Fertlactation) & $\square$ & $\square$ \\
$\square$ & $\square$ & Survival: Days of productive life (+146 & $\square$ & $\square$ \\
$\square$ & $\square$ & Health: Mastitis resistance (-6\% cases) & $\square$ & $\square$ \\
\hline
\end{tabular}

Figure 2. Example of best-worst choice task. The order of choice sets and of traits within each choice set was randomized based on the time at which respondents accessed the survey tool.

genetic improvement programs more generally. Definitions of resilience and efficiency, and a list of survey questions are provided in Appendix A in Supplemental Materials (https://doi.org/10.5281/zenodo.5713374).

A link to the online survey was disseminated to partners and stakeholders of the GenTORE project, and subsequently by those same partners and stakeholders, to relevant participants in their networks; Therefore, we followed a snowball-sampling approach. The survey was available in 7 languages to increase uptake; those languages were English, Danish, French, German, Italian, Spanish, and Swedish. Translated versions were

Table 1. The description of traits featured in the best-worst scaling choice experiment

\begin{tabular}{|c|c|c|}
\hline Trait group & Trait & Description \\
\hline Production & Protein yield & $\begin{array}{l}\text { A trait that describes milk protein produced per lactation. Protein content can be used an } \\
\text { indicator of milk quality. Ten years of selection on this trait could result in an extra } 3.3 \mathrm{~kg} \text { of } \\
\text { protein per lactation per cow. This is a } 1.3 \% \text { increase compared with current dairy cattle. }\end{array}$ \\
\hline Calving & Calving ease & $\begin{array}{l}\text { Level of assistance needed at calving. Ten years of selection on this trait could result in a } \\
\text { reduction of } 7 \% \text { in average calving difficulty score, meaning more unassisted calving and less cases } \\
\text { of calving difficulty. }\end{array}$ \\
\hline Maintenance & $\begin{array}{l}\text { Residual feed } \\
\text { intake (RFI) }\end{array}$ & $\begin{array}{l}\text { The difference between actual feed intake (DMI) and expected feed intake. Cattle that have } \\
\text { negative RFI values need less feed than would be expected to produce the same output. Ten } \\
\text { years of selection on this trait could result an RFI value of }-1.1 \mathrm{~kg} / \mathrm{d} \text {. Currently, most dairy cow } \\
\text { performance is between }+0.97 \text { to }-0.97 \mathrm{~kg} / \mathrm{d} \text {. }\end{array}$ \\
\hline Emissions & Methane emissions & $\begin{array}{l}\text { Methane produced per day per animal. Reducing methane emissions will reduce some of the } \\
\text { negative environmental impact of production. Ten years of selection on this trait could result in } \\
\text { a reduction of } 24 \mathrm{~g} \text { of methane produced per day per cow. This is an } 8 \% \text { decrease compared with } \\
\text { current lactating dairy cows. }\end{array}$ \\
\hline Health & Mastitis resistance & $\begin{array}{l}\text { Mastitis is a common disease in dairy systems, which has many effects ranging from loss of milk } \\
\text { to additional labor needed for treatment. Mastitis affects approximately } 14 \% \text { of dairy cows in } \\
\text { the first parity. Ten years of selection on this trait could result in a } 6 \% \text { reduction in first-parity } \\
\text { mastitis cases. }\end{array}$ \\
\hline Heat tolerance & $\begin{array}{l}\text { Milk production } \\
\text { in heat stress } \\
\text { conditions }\end{array}$ & $\begin{array}{l}\text { Normally, cows produce less milk under heat stress conditions. Selection on this trait will improve } \\
\text { the ability of cows to maintain production during warm weather periods. Ten years of selection on } \\
\text { this trait could result in an extra } 0.03 \mathrm{~L} \text { of milk per unit of heat stress above the threshold }(0.03 \\
\mathrm{L} \text { per unit of the temperature-humidity index above } 60) \text {. This could result in } 1 \% \text { more milk in the } \\
\text { warmer regions of Europe. }\end{array}$ \\
\hline
\end{tabular}


Table 2. Traits featured in the best-worst scaling choice experiment, together with genetic parameters $\left(h^{2}:\right.$ heritability; $\sigma p ;$ phenotypic standard deviation; $\mu$ : phenotypic mean), estimated response to selection $\left(R_{T}\right)$, unit of the trait, the response to selection as a percentage of the phenotypic mean $(\% \mathrm{G})$, and a reference for the genetic parameters

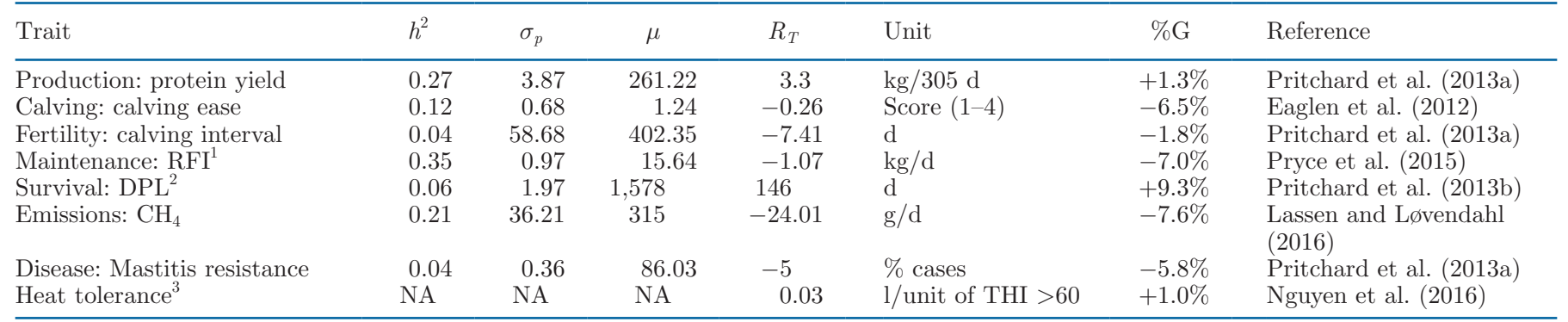

${ }^{1} \mathrm{RFI}=$ residual feed intake; response given in terms of reduction in feed intake based on mean daily feed intake.

${ }^{2} \mathrm{DPL}=$ days of productive life.

${ }^{3}$ Milk production in heat stress conditions: defined as the rate of decline in milk yield under heat stress conditions, $R_{T}$ taken directly from reference. THI = temperature-humidity index.

checked for consistency with the original English-language version by bilingual colleagues. The survey was live from March to April 2019.

\section{Response to Selection}

As mentioned, for each trait, we gave a response to selection that would be achievable if all selection emphasis was on that single trait, ignoring correlated effects. The reason for giving a response to selection was to ensure all respondents were conceptualizing the same level of improvement in each trait when making trade-offs between them. The response to selection was given in appropriate units for each trait and, for most traits, was calculated as the direct response to selection that could be achieved in a 4-pathway breeding scheme (Lush, 1945), ignoring genetic correlations as follows:

$$
R_{T j}=\frac{1}{4}\left(\sum_{n=1}^{4} i_{n}\right) h^{2} \sigma_{p}
$$

where $R_{T j}$ is the response to selection for trait $j, i_{n}$ is the selection intensity for each of the 4 selection pathways [sires of sires (i), sires of cows (ii), dams of sires (iii), and dams of cows (iv)]. The percentage of animals selected for breeding in each pathway was assumed to be 2.4, 10, 30 , and $100 \%$, respectively, giving respective selection intensities of 1.16, 1.75, 2.36 and 0.00 , which are representative of high input dairy cattle production systems (Nguyen et al., 2016). Heritability $\left(h^{2}\right)$ and phenotypic standard deviations $\sigma_{p}$ were taken from the literature. The $R_{T}$ for the heat tolerance trait was calculated differently, but in an equivalent way using accuracy and genetic standard deviation instead of heritability and phenotypic standard deviation, due to available genetic parameters. All $R_{T}$ and referenced parameters for their derivation can be found in Table 2. The generational response to selection, given by $R_{T}$, was scaled up to an estimated decadal response, as we wanted respondents to consider genetic change in the context of longer-term change in production circumstances. To do this, we assumed a generation interval of $2.5 \mathrm{yr}$ for bulls selected on the basis of genomic breeding values (pathways i-iii) and $5 \mathrm{yr}$ for cows (pathway iv). We also assumed a reduction in $R_{T}$ of $25 \%$ from the initial generation as a result of reduced genetic variance from selection itself (Falconer and Mackay, 1996; Simm, 1998).

\section{Econometric Analysis}

There are several approaches to analyzing BWS data, which range substantially in sophistication. The simplest approach is the count method, which describes the number of times trait $i$ is chosen as best minus the number of times trait $i$ is chosen as worst (herein, the B-W score). Despite the simplicity, the count method is appropriate for summarizing choice frequencies at the individual level and at the sample level (using the mean of individual B-W scores $\mu_{B-W}$; Auger et al., 2007). In fact, at these levels, results of the count method are highly correlated with more sophisticated probabilitybased statistical approaches, indicating that the count method provides a close approximation of the true value of items on the utility continuum (Louviere et al., 2015), as shown in Appendix B in Supplemental Materials (https://doi.org/10.5281/zenodo.5713374).

However, the count approach is not particularly useful for assessing how preferences differ between respondents. Commonly, in preference-based studies, heterogeneity may be explored using a priori stratification, by which the structures of respondent preference are 
grouped according to some observable characteristic of the respondents themselves, such as level of education (Zhou et al., 2018) or, in this case, respondent region. We assumed a portion of preference heterogeneity between respondents would be driven by the European region for which respondents were most knowledgeable. This is because future production challenges are likely to vary between regions (Gauly et al., 2013; Gauly and Ammer, 2020), meaning optimal strategies to mitigate such challenges, including genetic improvement strategies, may also vary. We used the count method with a priori stratification to summarize choice frequencies, grouping respondents based on European pedoclimatic regions (Metzger et al., 2005). On an interactive map, respondents were asked to indicate the region for which they had most experience and knowledge, and thus the region for which they would likely conceptualize future challenges to resilient and efficient production. However, summarizing results solely based on a priori stratification has limitations; one important limitation is a constraint on the variables with which heterogeneity can be explored, both in terms of numbers and observability (Auger et al., 2007; Deal, 2014).

Probability-based statistical models that are based on random utility theory offer more robust analytic options to account for preference heterogeneity. Here, we described the application of a latent class model (LCM), which allows the identification of discrete latent groups where preference heterogeneity is assumed to be driven by unobserved respondent characteristics, including attitudes, perceptions, experience, and beliefs, rather than easily observable sociodemographic factors (Zhou et al., 2018). In this way, LCM circumvent the limitations of a priori stratification methods by grouping respondents primarily according to their choice behavior (Boxall and Adamowicz, 2002). The output of LCM is a set of discrete preference classes. Conditional on the series of best-worst choices that respondents make, each respondent can be assigned a posterior probability of membership to each preference class. The allocation to classes follows a multinomial logit process, and preferences within each class are assumed to be homogeneous. A detailed description of the LCM is provided in Appendix C in Supplemental Materials (https://doi.org/10.5281/zenodo.5713374).

Defining the number of classes is an optimization process, where a parsimonious solution is sought to minimize the value of the model fit statistic (Bayesian information criterion) while maximizing the difference in preference structures between classes, and maximizing the percentage class membership (Colombo et al., 2009; Zhou et al., 2018). Based on these principles, we chose a 3 -class solution for both efficiency and resilience breeding goal contexts. Model fit plots and further details on this are provided in Appendix D in Supplemental Materials (https://doi.org/10.5281/ zenodo.5713374).

Notable outputs of the LCM are 2-fold. First, within each preference class, each trait is assigned a utility coefficient that describes its relative importance to class-members. Coefficients can be positive or negative values, and are given relative to a reference trait, which is omitted for model identification purposes. Interpretation of these coefficients is not intuitive, partly as similar values may not have the same meaning between classes because they can be subject to differences in scale. For this reason, we converted these utility coefficients into ratio-scaled impact scores, using a probability-based rescaling procedure (following Sawtooth Software Inc., 2008) as follows:

$$
\text { Ratio-scaled impact } \text { score }_{i s}=\frac{\exp \left(\theta_{i s}\right)}{\left(\exp \left(\theta_{i s}\right)+J-1\right)} \text {, }
$$

where $\theta_{i s}$ is the zero-centered utility weight for trait $i$ in class $s$ derived from the LCM, and, as previously stated, $J$ is the number of traits shown in each choice set $t$. These scores are then scaled from 0 to 100 points and can be easily interpreted as the predicted percentage of times a trait is selected as best by class-members, allowing comparison of scores across classes.

Second, each respondent is assigned a conditional probability of membership to each latent class. In our case, the highest conditional probability of membership to the 3 classes, per respondent, was high (see Supplemental File S4 for details), meaning the model distinguished the choice behavior of respondents between classes with low levels of ambiguity (Yoo, 2020). In this case, the highest conditional probability of class membership could be used to categorically assign respondents to 1 of the 3 latent classes. Therefore, although the preference classes were derived independently of observable characteristics of the respondent, it would still be possible to explore whether observed characteristics influenced the probability of class membership using postestimation analysis. Most commonly, this process of exploring trends in respondent characteristics between classes uses bivariate methods (Zhou et al., 2018); we used a Monte Carlo extension of the Chi-squared test (Hope, 1968).

Data management, summary statistics, descriptive statistics and postestimation analysis were performed in $\mathrm{R}$ (version 3.6.1; https://www.r-project.org/). Latent class analysis was performed in Stata (version 16; StataCorp LLC) using the package lclogit2 (Yoo, 2020). 


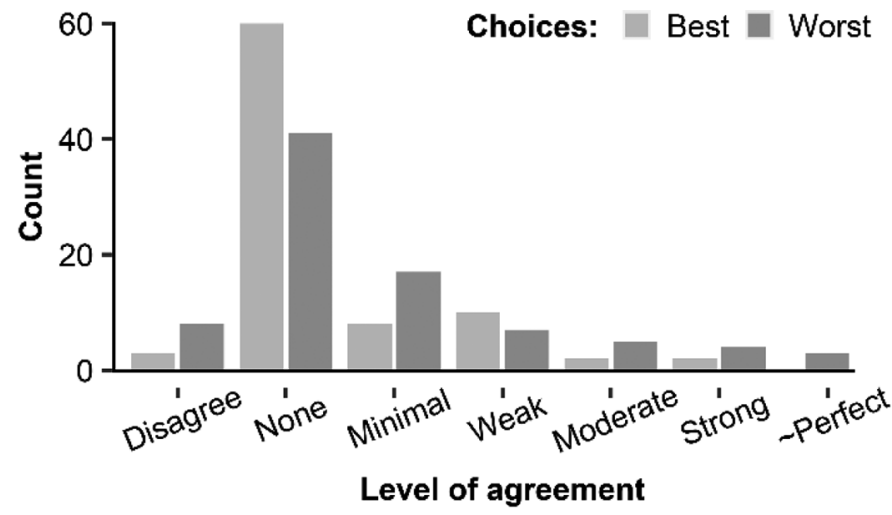

Figure 3. Agreement in all best and worst choices made by respondents across all choice sets between production goals, measured by Cohen's kappa. The discrete labels of the horizontal axis follow the recommended interpretation of Cohen's kappa by McHugh (2012).

\section{RESULTS AND DISCUSSION}

We received 85 responses from stakeholders across Europe, which is consistent with sample size recommendations for discrete choice experiments (de Bekker-Grob et al., 2015; Louviere et al., 2015); the sociodemographic characteristics of the respondents are summarized in Table 3. Each respondent completed 14 choice sets under 2 production scenarios (resilience and efficiency); each choice set contained 4 traits, giving a total of 19,040 observations. Overall, we found no evidence of agreement in the choices made by respondents for each production scenario (see Figure 3); this means that most respondents viewed these production goals as requiring different selection strategies.

\section{Trait Preferences}

The regionally aggregated mean B-W scores, derived using the count approach, are reported in Figure 4. Positive values of mean $\mathrm{B}-\mathrm{W}$ score occur when a trait is selected more times as best than as worst, with the opposite true for negative values. There are clear differences in the relative value of traits between the 2 production scenarios. For example, overall, the yield trait, protein yield, had the highest relative value in the efficiency scenario, whereas, in the resilience scenario, it was the least valued trait. A similar trend was evident for the maintenance trait, residual feed intake (RFI). Conversely, the relative values of the disease resistance trait, mastitis resistance, and the survival trait, days of productive life (DPL), increased in the resilience scenario. It was clear that some heterogeneity in the valuation of traits was driven by respondent region. For example, the value of the robustness trait, milk production in heat stress conditions (heat tolerance), in

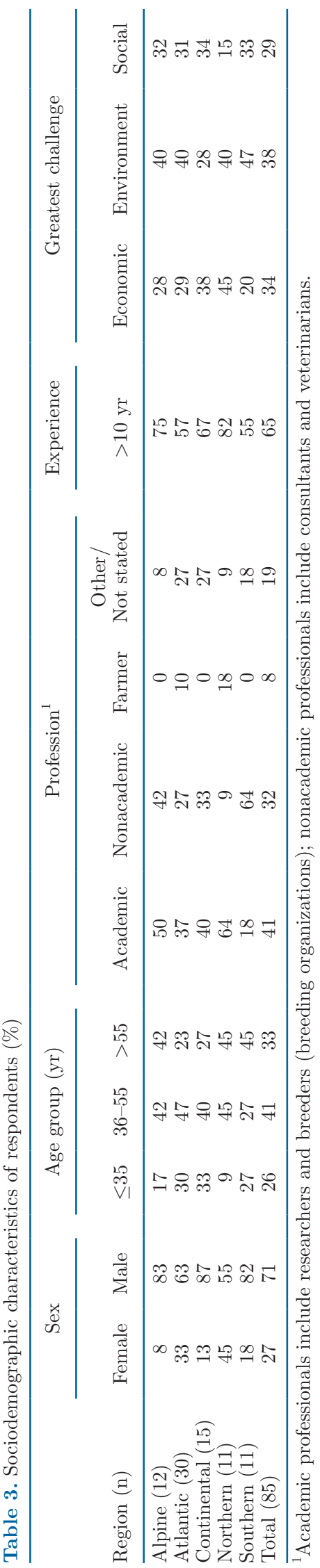




\section{Efficiency}

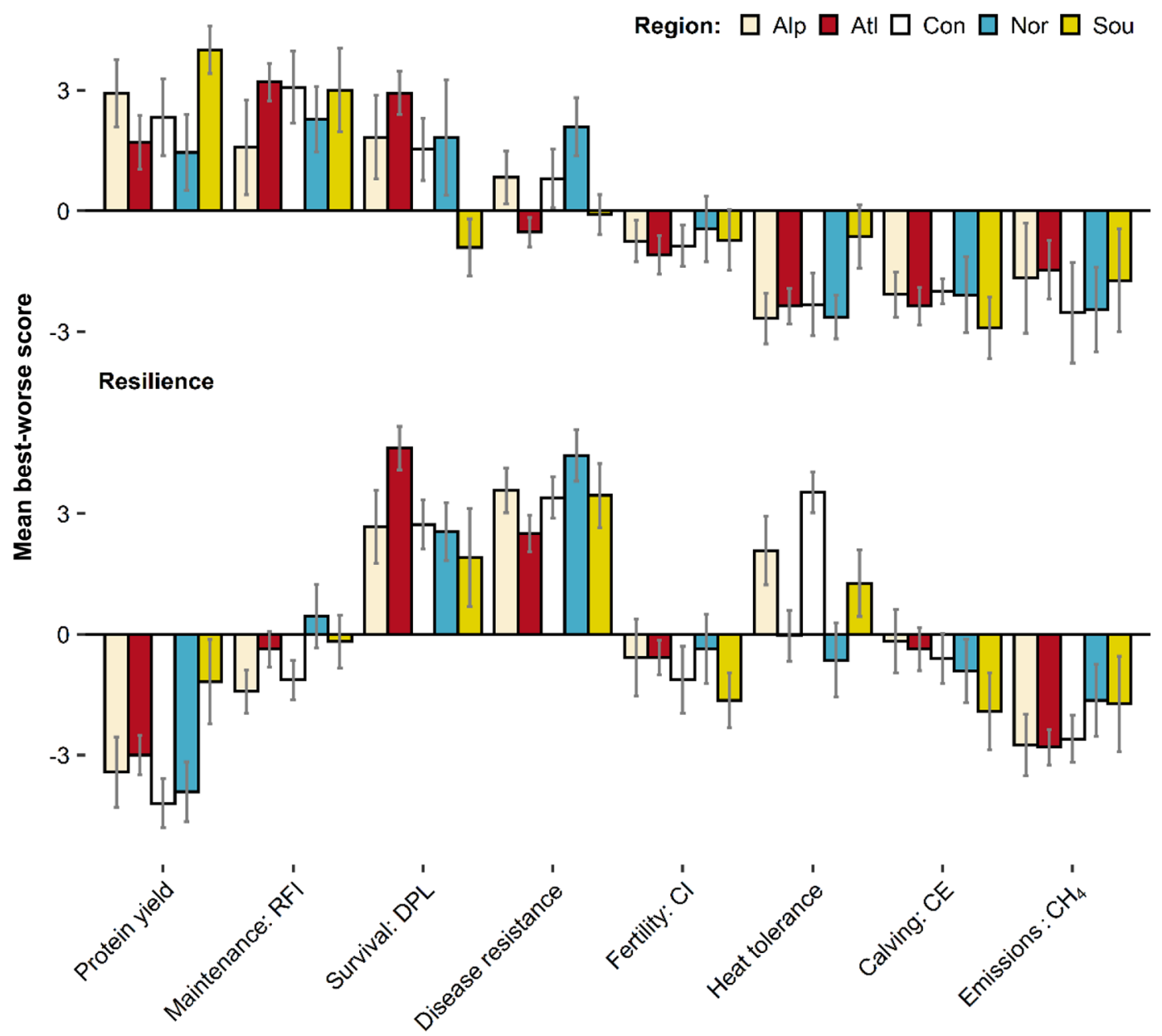

Figure 4. Mean best-worse score of genetic traits by region, with standard errors, where efficiency (top) is the production goal, and resilience (bottom) is the production goal. Regions are Alpine (Alp), Atlantic (Atl), Continental (Con), Northern (Nor) and Southern (Sou). RFI = residual feed intake; $\mathrm{DPL}=$ days of productive life; $\mathrm{CI}=$ calving interval; $\mathrm{CE}=$ calving ease.

the resilience scenario appeared quite different between respondents from Alpine, Continental, and Southern regions, who valued it higher than their Atlantic and Northern contemporaries. Furthermore, it was clear that respondents from the Southern region placed a higher value on the yield trait, protein yield, than other respondents in both scenarios. However, there was a general trend in which respondents appeared fairly consistent in their valuation of traits between regions.

Consequently, if drivers of heterogeneity in trait values were uncertain and complex, we could assume they were latent and explore the relative value of traits given these underlying latent constructs. Figures 5 and 6 describe the relative value of traits by members of 3 latent classes for each scenario. General trends in the relative value of traits within production goals and trade-offs between production goals were still evident. However, for each production goal, across classes, heterogeneity that was hidden in Figure 4 was now evident. For example, across classes in the efficiency scenario (Figure 5 ), there was substantial variation in the value placed on the DPL; at the extremes, it was the highest valued trait by members of class 1 , and the joint lowest valued trait by members of class 3 . As for the resilience scenario (Figure 6), there was a 10-fold difference in the value placed on protein yield across classes, with the class valuing this trait highest (class 3 ) comprising high, but not significantly disproportionate, membership of Southern European respondents $\left(\chi^{2}=5.93 ; P\right.$ $=0.048$ ).

There were additional examples of this hidden heterogeneity in the efficiency scenario (Figure 5). One such example that was not evident in Figure 4 was the substantial value placed on the environmental trait, 


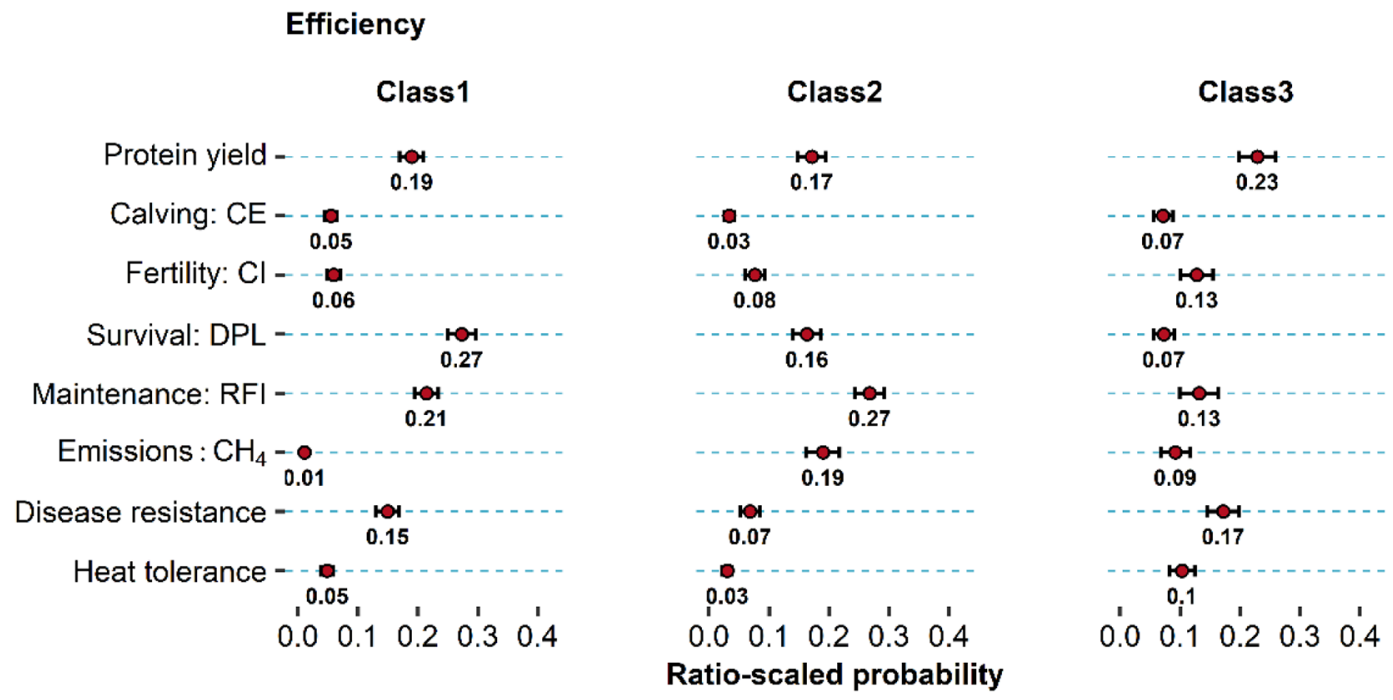

Figure 5. Latent class model-derived preference structures for respondents where efficiency is the production goal. As a percentage of the total sample, membership of each class was $46 \%, 30 \%$, and $24 \%$, respectively. $\mathrm{CE}=$ calving ease; $\mathrm{CI}=$ calving interval; $\mathrm{DPL}=$ days of productive life RFI = residual feed intake. See Appendix D in Supplemental Materials (https://doi.org/10.5281/zenodo.5713374) for raw utility estimates.

methane emissions, by members of class 2 ; respondents in class 2 were 19 times more likely to select this trait as best than respondents in class 1 . Incidentally, respondents who attained below university-level education were significantly more likely to be in efficiency class $1\left(\chi^{2}=10.96 ; P=0.004\right)$. Efficiency class 3 members valued the DPL among the least favorable traits, and they valued the robustness trait, heat tolerance, as the most favorable across all 3 classes. This class was not likely to have their preferences well represented by class 2 of the resilience scenario (Figure $6 ; \chi^{2}=8.81 ; P$ $=0.010)$, perhaps unsurprising given the oppositional value of some traits, including the 2 aforementioned.

Across the resilience scenario classes in Figure 6, some trends mirrored those evident in Figure 4. For instance, in all 3 resilience classes, DPL and mastitis resistance were consistently the most highly valued traits. Additionally, for members of class 1 and class 3 , who comprised $84 \%$ of all respondents, heat tolerance was the third most valuable trait. For resilience class 2 ,

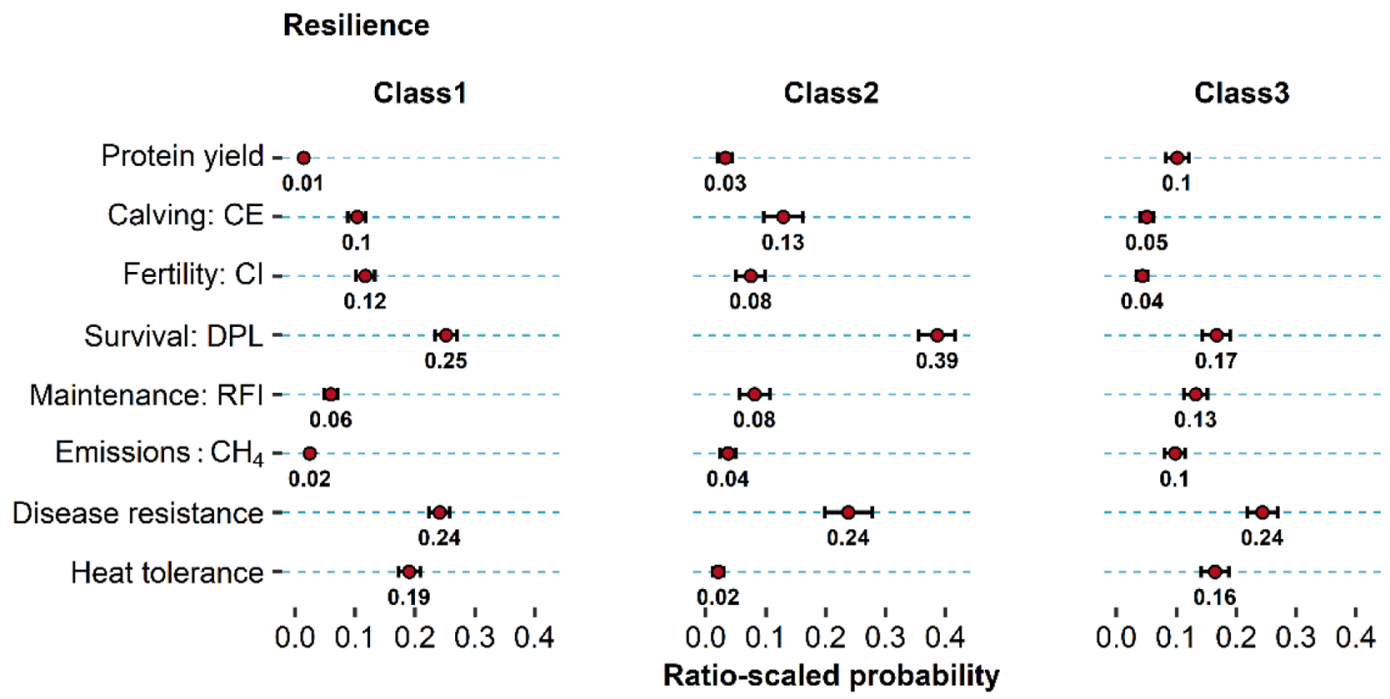

Figure 6. Latent class model-derived preference structures for respondents where resilience is the production goal. As a percentage of the total sample, membership of each class was $52 \%, 16 \%$ and $32 \%$, respectively. $\mathrm{CE}=$ calving ease; $\mathrm{CI}=$ calving interval; $\mathrm{DPL}=$ days of productive life; RFI = residual feed intake. See Appendix D in Supplemental Materials (https://doi.org/10.5281/zenodo.5713374) for raw utility estimates. 
in which heat tolerance was assigned the lowest value, we found disproportionate membership of farmers $\left(\chi^{2}\right.$ $=10.32 ; P=0.009$ ), although uneven sampling was notable here. Farmer respondents were from Northern and Atlantic regions of Europe, where they may not perceive heat tolerance as a potential problem. Incidentally, resilience class 2 was also the class that designated a substantially high value to DPL.

An important component of the choice exercise was the availability of a theoretical improvement in each trait. Thus, it was useful to consider the available improvement in each trait as proportionate to the utility value assigned to it by class-members (Sae-Lim et al., 2012). Table 4 gives an example of the expected gains in each trait if selection was weighted according to the utility values of the most populous class for each production goal, and if traits were independent (the full table can be found in Appendix E in Supplemental Materials, https://doi.org/10.5281/zenodo.5713374). Evidently, for efficiency class 1, although there was similar value placed on protein yield and RFI, it translated to less similar improvements when selection was weighted by utility values. This was because, for each trait under independent selection, the rate of genetic change was not only influenced by the selection emphasis (i.e., the utility value), but also by the heritability and phenotypic coefficient of variation (Table 2.).

A novel application of the BWS conjoint valuation method was used to determine the change in utility value of a set of genetic traits under 2 production goals, resilient and efficient production. We highlighted tradeoffs in the value of some traits under these 2 goals, indicating the potential for antagonisms in maintaining efficient production that is also resilient to expected changes in future production circumstances. The results of this study confirmed the existence of heterogeneity in the views of stakeholders, which added to a growing body of evidence (Byrne et al., 2016; Slagboom et al., 2016; Just et al., 2018). However, we found more consistency in the value of traits when selecting for resilience, with greater heterogeneity if the goal was efficiency. Furthermore, we combined utility values with the maximum genetic improvement possible for each trait to estimate the expected gains in each trait if traits were independently selected.

\section{General Trends in Trait Value}

In terms of efficient production, at the sample level, the most valued trait was the yield trait, protein yield, followed by the maintenance trait, RFI, and the survival trait, DPL. However, on accounting for latent classes of heterogeneity, we found the health trait, mastitis resistance, the environmental trait, methane emissions, and the fertility trait, calving interval, all featured in the top 3 in 1 of the 3 classes. In fact, only 1 class contained all 3 of the most preferred traits at the sample level; however, they were valued in the opposite order. If none of the 3 efficiency classes were accurately represented by the mean of the whole sample, this evidenced the notion that ignoring preference heterogeneity risked misrepresenting the beliefs of the entire sample as stakeholders did not agree on where to put emphasis for more efficient production. A similar trend in the misrepresentation of preferences at the sample level was found by Martin-Collado et al. (2015). Hence, the correct identification of respondent groups, who shared similar values, was highly important in increasing the relevance of recommendations and, in turn, the likelihood of adoption into practice (Nielsen et al., 2014). Many of the traits we found most valued for an efficiency goal, where efficiency was the central thesis of contemporary production systems, also featured high in comparable studies from Denmark (Slagboom et al., 2016), Australia (Martin-Collado et al., 2015), Finland (Paakala et al., 2020), and Germany (Just et al., 2018).

For resilient production, in all but one class, the most valued traits at the sample level were also the most

Table 4. Maximum percentage gains (\%G), if traits were independent, relative to the phenotypic mean, and percentage gains if selection was weighted according to the utility values of the most populous class (class 1 ) for each production goal (desired \%G)

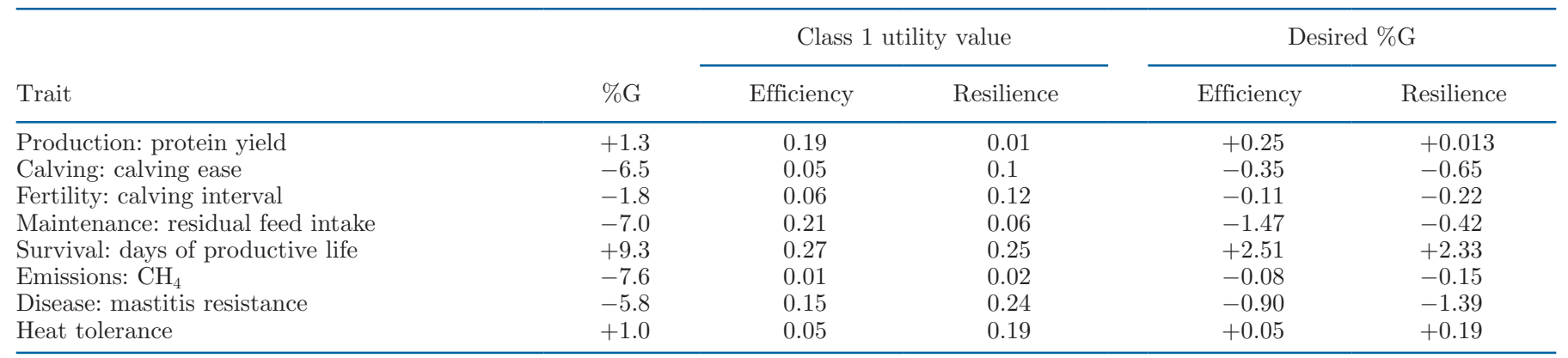


valued traits at the class level. These were mastitis resistance, the DPL, and the robustness trait, heat tolerance. For the class with disproportionate membership of farmers, the robustness trait was traded for the calving trait, calving ease. Because strategies for resilient production are dependent on the specific challenges experienced between production environments (Friggens et al., 2017), one might have expected to see more heterogeneity here than under scenarios of efficient production, as efficiency is a well-embedded concept in the field of genetic improvement (Simm, 1998). However, resilience is a relatively new concept in the context of animal breeding and management, which may not be sufficiently well researched to enable the development of diverse mitigation strategies. It is likely that respondents related to resilience in a mixed way, drawing on aspects of robustness and adaptability, but we cannot know for sure, and future research may seek to quantify the contribution of different components of resilience in stakeholder understanding. A blended interpretation of resilience may also have driven a high value for DPL because, for many, this trait may have been representative of a broad measure of resilience, indicating an individual's ability to overcome a multitude of challenges and repeatedly avoid mortality, whether by voluntary or involuntary culling (Friggens et al., 2017).

Despite a high degree of uncertainty in predicting future production circumstances, some specific effects are generally agreed upon and increasingly well researched. One such effect is heat stress, an issue expected to intensify across Europe (Carabaño et al., 2017; EEA, 2017). Heat stress is predicted to drive losses in performance of production and functional traits (Wall et al., 2010b; Hill and Wall, 2015, 2017; Gauly and Ammer, 2020) including increasing susceptibility to disease, which will exacerbate existing challenges such as mastitis control (Vitali et al., 2020). This may motivate the inflated value of the robustness trait and health trait to respondents in the resilience scenario. Further, the most severe effects of heat stress were expected in Alpine, Continental, and Southern regions, supporting a trend for respondents in these regions to value the robustness trait (Figure 4). In fact, in the resilience scenario, only the class containing disproportionate membership of farmers (resilience class 2, Figure 6) did not highly value the robustness trait. In this regard, it was also interesting that the environmental trait, methane emissions, was valued in the efficiency scenario but less so in the resilience scenario; continued emissions may not only affect production via market drivers related to consumer demand but will also have direct effects on animals as emissions contribute to continued climate change, driving further requirements for robustness and adaptation.

\section{Trade-offs and Synergies}

The value increase of traits in the resilience scenario came at the expense of some traits highly valued in the efficiency scenario. Notably, protein yield and RFI had a substantial decrease in value between scenarios. Yield traits are rarely considered in contemporary conceptualizations of the future cow (Pryce et al., 2009; Calus et al., 2013; Friggens et al., 2017). Despite the importance of such traits to the system, the low value in the context of resilience is indicative of a general consensus that maximal production is less important than persistent and undeviating production (Elgersma et al., 2018; Poppe et al., 2020). The reason is clear when considering that highly productive animals are also more perturbed by variable production environments than their genetically inferior herd-mates (Hill and Wall, 2015), and that maximizing short-term gains can come at the expense of longer-term functional fitness (Rauw et al., 1998; Seedorf et al., 1998; FuerstWaltl et al., 2016; Puillet et al., 2016; Friggens et al., 2017). Similarly, a recent study of trait preferences of German dairy farmers by Just et al. (2018) found the value respondents placed on a novel health trait came at the expense of value placed on milk yield.

However, it is less clear why RFI was valued so low in the resilience scenario. Reducing required feed intake for the same unit output has benefits for efficient production (Connor, 2015), but perhaps the benefits for resilient production are less clear. Respondents may not have considered the indirect effects of more variable production circumstances, such as potential reductions in the availability and quality of feed, stemming from environmental or social pressures (Thornton, 2010; FAO, 2017; Dellar et al., 2018). In a future that involves such nutritional challenges, the efficient conversion of feed would surely offer a synergistic opportunity toward resilience and efficiency goals. Therefore, the failure of respondents to identify this trait as valuable for resilient production suggests a failure in knowledge exchange, which, if not corrected, may delay top-down support for more appropriate selection objectives.

The survival trait, DPL, was highly valued in both production scenarios by most respondents. In this sense, it was seen by many as a mutually beneficial trait in terms of future efficiency and resilience. Improving survival conveys benefits via all 3 sustainability pillars (economic, environmental, and social), and the high value here is mirrored in other studies (Martin-Collado et al., 2015; Paakala et al., 2020). In economic terms, increasing longevity will bring substantial savings to the farm enterprise, not only by reducing young stock requirements but also by avoiding unnecessary investment in an individual if accurate predictions can be made 
about her survival ability at a young age (Pritchard et al., 2013a). This is especially true because heiferrearing costs are among the highest variable costs to the farm (Chamberlain, 2012). In environmental terms, for roughly the improvements in survival presented to respondents here, Wall et al. (2010a) estimate reductions in both methane and nitrous oxide of $\sim 20 \%$ at the herd level, driven by changes in both herd age structure and young stock requirements. Moreover, in some ways, survival is also beneficial to social concerns such as animal welfare (Oltenacu and Algers, 2005; Vasseur, 2017). However, as genetic improvement is continual and accelerating, retaining cows for longer in the herd will increase the genetic difference between the average cow and the average genetically improved replacement; therefore, improving survival is associated with greater genetic lag. In this way, when consideration is given to losses in maintaining older cows in the herd compared with the opportunity gains of genetically superior replacements, the economic optimality of longevity may be somewhat reduced (De Vries, 2017). To counteract such losses, researchers may seek the optimal combination of culling and reproductive technologies - for example, using sexed semen (Clasen et al., 2019) and an apt culling index (Kelleher et al., 2015) - which is not yet determined (De Vries, 2017).

\section{Preference Heterogeneity}

In the present study, we found some sociodemographic characteristics explaining variation in choices, and resultantly, class membership (full details can be found in Appendix F in Supplemental Materials, https://doi .org/10.5281/zenodo.5713374). For instance, lower education was a driver of membership to the class placing least value on the methane emissions. Previous research has highlighted similar findings in terms of predictors of trait preference, such as Just et al. (2018), Makokha et al. (2007) and Martin-Collado et al. (2014), who found education to be associated with farmer trait preferences. We also presented trait values as a function of respondent region. However, trends of regional differences in preference seen in Figure 4 were not substantiated by significant associations in the LCM postestimation.

In our sample, we found profession to be related to membership of one class, meaning there may be differences in the value of traits between stakeholders in different segments of our system. If true at the population level, this may indicate a disconnect between stakeholders implementing genetic change at the herd level (i.e., farmers), and those directing change at the national-level (i.e., breeders and researchers). However, given our relatively small sample, which is unlikely to be representative of the whole stakeholder population, we cautiously posit this only as an observation. Further research may investigate whether such complex drivers of preference may prevent unified approaches to selecting for a resilient future cow (Martin-Collado et al., 2018), and whether improved knowledge exchange, for example via extension services or interdisciplinary collaborations in research, can mitigate this eventuality. This is especially important as the value placed on resilience traits will likely be proportional to the type and extremity of future perturbations expected by the respondent; however, there is uncertainty around future production circumstances, and the multifarious risk of not preparing livestock to deal with such challenges may not be understood by all stakeholders equally (Barnes and Toma, 2012).

\section{Methodological Reflection}

We used a novel application of the conjoint valuation method, BWS (Louviere et al., 2015). The method was particularly appropriate, given its ability to return accurate and robust utility estimates, without requiring a particularly large sample size (relative to more traditional discrete choice frameworks), as well as its commensuration to approaches useful in uncovering heterogeneous valuation such as LCM (Cheung et al., 2016, 2019). The BWS approach differs from alternative discrete choice experiments, where respondents may only be required to select the best item in each choice set or may be required to rank all items in each choice set. Although the former completely ignores information on the less attractive items, which affects the discriminatory power of the approach, especially for those traits that may not regularly be chosen as best, the latter can be highly cognitively demanding for respondents, especially when repeated over several choice sets (Mangham et al., 2009; Potoglou et al., 2011). Additionally, with full rankings, it is likely that choices regarding items at the extreme ends of the scale are more reliable than choices regarding those items in the middle when respondents evaluate a set of items on a latent subjective scale (Helson, 1964; Louviere et al., 2013). The BWS addresses these limitations by capturing some information on the nonchosen traits without overburdening respondents with unnecessarily complex tasks (Louviere et al., 2015). Some recent studies also use pairwise comparison methods. Licensed software may be a barrier here (Martin-Collado et al., 2015; Slagboom et al., 2016), although this is not always the case (Sae-Lim et al., 2012; Paakala et al., 2020). The method we presented offers an additional option to a growing toolbox of approaches appropriate for deriving trait values based on preferences, and future research may seek to quantify the dependency of outcomes on 
methodological choices. It is important to state that the value we derived from the choices of respondents was not purely financial but encapsulated other motivations and values (Nielsen et al., 2014, 2011), which drives the heterogeneity found here and in similar studies.

There are some limitations to our study that warrant discussion. As with most survey research, a larger sample size is usually desired for statistical power (Cohen, 1988). Many factors can affect participation, and, in our case, it is likely that completion time might have been a factor for relatively low sample size in some strata. We also aimed to engage with a broad and diverse set of stakeholders, which is in contrast to the vast majority of preference-based research in this field that usually focuses exclusively on farmers without characterizing the views of other important stakeholder groups (e.g., Slagboom et al., 2016; Just et al., 2018). Our sampling strategy was appropriate for that purpose; however, if we wanted to obtain a representative sample of a single stakeholder group, especially of farmers, a probabilistic sampling approach based on a clearly defined sampling frame is preferable in terms of delivering generalizable results. Because a truly representative sample of our target population, including more stakeholder groups, was not possible within the constraints of this study, the results should be interpreted with the awareness that there was bias in the sample. With respect to farmers, for example, it is likely that our results captured the view of farmers with a relatively greater interest in issues of breeding and genetic selection. Further research should seek a more targeted sampling approach to explore different views of stakeholder groups across production systems, which could possibly include a combination of qualitative interviews and workshops to investigate such trends in more detail. Nevertheless, we did uncover some notable trends, some of which were significant in our sample, that are reflected in comparable studies noted previously.

Overall, preference-based approaches can be useful both in complementing conventional formulation of breeding objectives (Sae-Lim et al., 2012; Byrne et al., 2016) and as a first step toward identifying segments of the industry where disparate expectations of future production may account for some of these differences (Sy et al., 1997). In each case, the outcome presents opportunities to increase relevance and likely uptake of breeding objectives, either by better accounting for heterogeneous objectives or by guiding targeted improvements in knowledge exchange.

\section{CONCLUSIONS}

There was clear heterogeneity in the values of genetic improvement under different production scenarios.
Some of this heterogeneity was explained by sociodemographic characteristics of the respondents, but many trade-offs were ubiquitous. From the efficiency goal to the resilience goal, we found a substantial drop in value for protein yield and RFI. In the same direction, value increased for heat tolerance and mastitis resistance. The survival trait, DPL, appeared to offer synergistic opportunities between the 2 production goals; however, the usefulness of this trait in promoting resilience will depend on phenotyping across diverse production environments, where individuals may be exposed to diverse perturbations (Friggens et al., 2017). As resilience becomes increasingly important, it is likely that a continued reliance on the short-term economic value of traits alone will lead decision makers to underestimate the importance of some traits, including those with substantial contextual values in terms of resilience. Preference-based approaches, such as the BWS method presented here, offer a straightforward means to achieve the defensible inclusion of such strategic values.

\section{ACKNOWLEDGMENTS}

This work is part of the GenTORE project that received funding from the European Union's Horizon 2020 research and innovation program, under grant agreement No. 727213. The survey was approved by the University of Edinburgh (Human) Ethics Research Committee. The authors thank the following people for support in translating the survey: Florian Leiber (FiBL, Switzerland), Lotta Rydhmer (SLU, Sweden), Simon Moakes (FiBL, Switzerland), Isabel Casasús Pueyo (CITA, Spain), Laurence Puillet (INRAE, France), Isabella Lora (UniPD, Italy), Florian Payen (SRUC, Scotland), Cathrine Erichsen (SRUC, Scotland), Karin Alvåsan (SLU, Sweden), and Fernando Agra-Lorenzo (SRUC, Scotland). The authors also extend thanks to all participants and to 2 anonymous reviewers for recommending improvements to an earlier version of this manuscript. The authors have not stated any conflicts of interest.

\section{REFERENCES}

Aizaki, H., 2020. support.BWS: Tools for Case 1 Best-Worst Scaling. https://cran.r-project.org/web/packages/support.BWS/support .BWS.pdf.

Aizaki, H., T. Nakatani, and K. Sato. 2014. Best-worst scaling. Pages 133-174 in Stated Preference Methods Using R. CRC Press.

Auger, P., T. M. Devinney, and J. J. Louviere. 2007. Using best-worst scaling methodology to investigate consumer ethical beliefs across countries. J. Bus. Ethics 70:299-326. https://doi.org/10.1007/ s10551-006-9112-7.

Barnes, A. P., and L. Toma. 2012. A typology of dairy farmer perceptions towards climate change. Clim. Change 112:507-522. https:// doi.org/10.1007/s10584-011-0226-2. 
Berghof, T. V. L., M. Poppe, and H. A. Mulder. 2019. Opportunities to improve resilience in animal breeding programs. Front. Genet. 9:692. https://doi.org/10.3389/fgene.2018.00692.

Bos, J. M., H. van den Belt, and P. H. Feindt. 2018. Animal welfare, consumer welfare, and competition law: The Dutch debate on the chicken of tomorrow. Anim. Front. 8:20-26. https://doi.org/10 1093/af/vfx001.

Boxall, P. C., and W. L. Adamowicz. 2002. Understanding heterogeneous preferences in random utility models: A latent class approach. Environ. Resour. Econ. 23:421-446. https://doi.org/10 $.1023 / \mathrm{A}: 1021351721619$

Brascamp, E. W., C. Smith, and D. R. Guy. 1985. Derivation of economic weights from profit equations. Anim. Prod. 40:175-179. https://doi.org/10.1017/S0003356100031986.

Bullock, J. M., K. L. Dhanjal-Adams, A. Milne, T. H. Oliver, L. C. Todman, A. P. Whitmore, and R. F. Pywell. 2017. Resilience and food security: Rethinking an ecological concept. J. Ecol. 105:880884. https://doi.org/10.1111/1365-2745.12791.

Busch, G., and A. Spiller. 2018. Consumer acceptance of livestock farming around the globe. Anim. Front. 8:1-3. https://doi.org/10 .1093/af/vfx005

Byrne, T. J., B. F. S. Santos, P.R. Amer, D. Martin-Collado, J.E Pryce, and M. Axford.,. 2016. New breeding objectives and selection indices for the Australian dairy industry. J. Dairy Sci. 99:8146-8167. https://doi.org/10.3168/jds.2015-10747.

Calus, M. P. L., D. P. Berry, G. Banos, Y. de Haas, and R. F. Veerkamp. 2013. Genomic selection: The option for new robustness traits? Adv. Anim. Biosci. 4:618-625. https://doi.org/10.1017/ s2040470013000186.

Carabaño, M. J., M. Ramón, C. Díaz, A. Molina, M. D. Pérez-Guzmán, and J. M. Serradilla. 2017. Breeding for resilience to heat stress effects in dairy ruminants. A comprehensive review. J. Anim. Sci. 95:1813-1826. https://doi.org/10.2527/jas2016.1114

Chamberlain, T. 2012. Understanding the economics of dairy farming Part 1: Income, costs and profit. UK Vet Livest. 17:30-33.

Chawala, A. R., G. Banos, A. Peters, and M. G. G. Chagunda. 2019. Farmer-preferred traits in smallholder dairy farming systems in Tanzania. Trop. Anim. Health Prod. 51:1337-1344. https://doi .org/10.1007/s11250-018-01796-9.

Cheung, K. L., S. Mayer, J. Simon, H. de Vries, S. M. A. A. Evers, I E. H. Kremer, and M. Hiligsmann. 2019. Comparison of statistical analysis methods for object case best-worst scaling. J. Med. Econ. 22:509-515. https://doi.org/10.1080/13696998.2018.1553781.

Cheung, K. L., B. F. M. Wijnen, I. L. Hollin, E. M. Janssen, J. F. Bridges, S. M. A. A. Evers, and M. Hiligsmann. 2016. Using bestworst scaling to investigate preferences in health care. PharmacoEconomics 34:1195-1209. https://doi.org/10.1007/s40273-016 $-0429-5$

Clasen, J. B., J. O. Lehmann, J. R. Thomasen, S. Østergaard, and M. Kargo. 2019. Combining extended lactation with sexed semen in a dairy cattle herd: Effect on genetic and total economic return. Livest. Sci. 223:176-183. https://doi.org/10.1016/j.livsci.2019.03.001.

Cohen, J. 1988. Statistical Power Analysis for the Behavioral Sciences. 2nd ed. Academic Press.

Colditz, I. G., and B. C. Hine. 2016. Resilience in farm animals: Biology, management, breeding and implications for animal welfare. Anim. Prod. Sci. 56:1961-1983. https://doi.org/10.1071/AN15297.

Colombo, S., N. Hanley, and J. Louviere. 2009. Modeling preference heterogeneity in stated choice data: An analysis for public goods generated by agriculture. Agric. Econ. 40:307-322. https://doi .org/10.1111/j.1574-0862.2009.00377.x

Connor, E. E. 2015. Invited review: Improving feed efficiency in dairy production: Challenges and possibilities. Animal 9:395-408. https: //doi.org/10.1017/S1751731114002997.

Darnhofer, I. 2014. Resilience and why it matters for farm management. Eur. Rev. Agric. Econ. 41:461-484. https://doi.org/10.1093/ erae/jbu012.

de Bekker-Grob, E. W., B. Donkers, M. F. Jonker, and E. A. Stolk. 2015. Sample size requirements for discrete-choice experiments in healthcare: A practical guide. Patient 8:373-384. https://doi.org/ 10.1007/s40271-015-0118-z.
De Vries, A. 2017. Economic trade-offs between genetic improvement and longevity in dairy cattle. J. Dairy Sci. 100:4184-4192. https:/ /doi.org/10.3168/jds.2016-11847.

Deal, K. 2014. Segmenting patients and physicians using preferences from discrete choice experiments. Patient 7:5-21. https://doi.org/ 10.1007/s40271-013-0037-9.

Dellar, M., C. F. E. Topp, G. Banos, and E. Wall. 2018. A metaanalysis on the effects of climate change on the yield and quality of European pastures. Agric. Ecosyst. Environ. 265:413-420. https: //doi.org/10.1016/j.agee.2018.06.029.

Eaglen, S. A. E., M. P. Coffey, J. A. Woolliams, and E. Wall. 2012 Evaluating alternate models to estimate genetic parameters of calving traits in United Kingdom Holstein-Friesian dairy cattle. Genet. Sel. Evol. 44:23. https://doi.org/10.1186/1297-9686-44-23.

EEA (European Environment Agency). 2017. Climate change, impacts and vulnerability in Europe 2016. Accessed Sep. 19, 2020. https:] /op.europa.eu/en/publication-detail/-/publication/794dcba3-e922 -11e6-ad7c-01aa75ed71a1/language-en.

Elgersma, G. G., G. de Jong, R. van der Linde, and H. A. Mulder. 2018. Fluctuations in milk yield are heritable and can be used as a resilience indicator to breed healthy cows. J. Dairy Sci. 101:12401250. https://doi.org/10.3168/jds.2017-13270.

Falconer, D. S., and T. F. C. Mackay. 1996. Introduction to Quantitative Genetics. 4th ed. Longman.

FAO (Food and Agriculture Organization of the United Nations). 2017. The future of food and agriculture: Trends and challenges Accessed Sep. 19, 2020. https://www.fao.org/3/i6583e/i6583e.pdf.

Friggens, N. C., F. Blanc, D. P. Berry, and L. Puillet. 2017. Review: Deciphering animal robustness. A synthesis to facilitate its use in livestock breeding and management. Animal 11:2237-2251. https: //doi.org/10.1017/S175173111700088X.

Fuerst-Waltl, B., C. Fuerst, W. Obritzhauser, and C. Egger-Danner. 2016. Sustainable breeding objectives and possible selection response: Finding the balance between economics and breeders' preferences. J. Dairy Sci. 99:9796-9809. https://doi.org/10.3168/jds 2016-11095.

Gauly, M., and S. Ammer. 2020. Review: Challenges for dairy cow production systems arising from climate changes. Animal 14:s196203. https://doi.org/10.1017/S1751731119003239.

Gauly, M., H. Bollwein, G. Breves, K. Brügemann, S. Dänicke, G. Daş, J. Demeler, H. Hansen, J. Isselstein, S. König, M. Lohölter, M. Martinsohn, U. Meyer, M. Potthoff, C. Sanker, B. Schröder, N. Wrage, B. Meibaum, G. Von Samson-Himmelstjerna, H. Stinshoff, and C. Wrenzycki. 2013. Future consequences and challenges for dairy cow production systems arising from climate change in Central Europe - A review. Animal 7:843-859. https://doi.org/10 .1017/S1751731112002352.

Ge, L., N. P. Anten, I. D. E. van Dixhoorn, P. H. Feindt, K. Kramer, R. Leemans, M. P. Meuwissen, H. Spoolder, and W. Sukkel. 2016 Why we need resilience thinking to meet societal challenges in biobased production systems. Curr. Opin. Environ. Sustain. 23:17-27. https://doi.org/10.1016/j.cosust.2016.11.009.

Groen, A. F. 1989. Cattle breeding goals and production circumstances. PhD thesis. Department of Farm Management and Department of Animal Breeding, Wageningen Agricultural University, Wageningen, The Netherlands. https://edepot.wur.nl/134033.

Helson, H. 1964. Adaptation-Level Theory. Harper \& Row.

Hill, D. L., and E. Wall. 2015. Dairy cattle in a temperate climate: The effects of weather on milk yield and composition depend on management. Animal 9:138-149. https://doi.org/10.1017/ S1751731114002456.

Hill, D. L., and E. Wall. 2017. Weather influences feed intake and feed efficiency in a temperate climate. J. Dairy Sci. 100:2240-2257. https://doi.org/10.3168/jds.2016-11047.

Holling, C. S. 1973. Resilience and stability of ecological systems. Annu. Rev. Ecol. Syst. 4:1-23. https://doi.org/10.1146/annurev.es 04.110173.000245.

Hope, A. C. A. 1968. A simplified Monte Carlo significance test procedure. J. R. Stat. Soc. Series B Stat. Methodol. 30:582-598.

Just, A., R. Wellmann, and J. Bennewitz. 2018. Estimation of relative economic weights and the marginal willingness to pay for breeding 
traits of Brown Swiss cattle using discrete choice experiments. J. Dairy Sci. 101:5207-5213. https://doi.org/10.3168/jds.2017-14012.

Kelleher, M. M., P. R. Amer, L. Shalloo, R. D. Evans, T. J. Byrne, F, Buckley, and D. P. Berry. 2015. Development of an index to rank dairy females on expected lifetime profit. J. Dairy Sci. 98:42254239. https://doi.org/10.3168/jds.2014-9073.

Kipling, R. P., A. Bannink, G. Bellocchi, T. Dalgaard, N. J. Fox, N. J. Hutchings, C. Kjeldsen, N. Lacetera, F. Sinabell, C. F. E. Topp, M. van Oijen, P. Virkajärvi, and N. D. Scollan. 2016. Modeling European ruminant production systems: Facing the challenges of climate change. Agric. Syst. 147:24-37. https://doi.org/10.1016/j .agsy.2016.05.007.

Kipling, R. P., C. F. E. Topp, A. Bannink, D. J. Bartley, I. BlancoPenedo, R. Cortignani, A. del Prado, G. Dono, P. Faverdin, A.-I. Graux, N. J. Hutchings, L. Lauwers, Ş. Özkan Gülzari, P. Reidsma, S. Rolinski, M. Ruiz-Ramos, D. L. Sandars, R. Sándor, M. Schönhart, G. Seddaiu, J. van Middelkoop, S. Shrestha, I. Weindl, and V. Eory. 2019. To what extent is climate change adaptation a novel challenge for agricultural modellers? Environ. Model. Softw. 120:104492. https://doi.org/10.1016/j.envsoft.2019.104492.

Kovats, R. S., R. Valentini, L. M. Bouwer, E. Georgopoulou, D. Jacob, E. Martin, M. Rounsevell, and J. Soussana. 2014. Europe, Pages 1267-1326 in Climate Change 2014: Impacts, Adaptation, and Vulnerability. Part B: Regional Aspects. Contribution of Working Group II to the Fifth Assessment Report of the Intergovernmental Panel on Climate Change. V. R. Barros, C. B. Field, D. J. Dokken, M. D. Mastrandrea, K. J. Mach, T. E. Bilir, M. Chatterjee, K. L. Ebi, Y. O. Estrada, R. C. Genova, B. Girma, E. S. Kissel, A. N. Levy, S. MacCracken, P. R. Mastrandrea, and L. L. White, eds. Cambridge University Press.

Lancaster, K. 1966. A new approach to consumer theory. J. Polit. Econ. 74:132-157. https://doi.org/10.1086/663168.

Lassen, J., and P. Løvendahl. 2016. Heritability estimates for enteric methane emissions from Holstein cattle measured using noninvasive methods. J. Dairy Sci. 99:1959-1967. https://doi.org/10 $.3168 /$ jds.2015-10012.

Louviere, J., T. Flynn, and A. Marley. 2015. Best-Worst Scaling: Theory, Methods and Applications. Cambridge University Press.

Louviere, J., I. Lings, T. Islam, S. Gudergan, and T. Flynn. 2013. An introduction to the application of (case 1) best-worst scaling in marketing research. Int. J. Res. Mark. 30:292-303. https://doi .org/10.1016/j.ijresmar.2012.10.002.

Lush, J. L. 1945. Animal Breeding Plans. 3rd ed. Iowa State University Press.

Makokha, S. N., J. T. Karugia, S. J. Staal, and W. Oluoch-kosura 2007. Valuation of cow attributes by conjoint analysis: A case study of Western Kenya. Afr. J. Agric. Resour. Econ. 1:95-113.

Mangham, L. J., K. Hanson, and B. McPake. 2009. How to do (or not to do)...Designing a discrete choice experiment for application in a low-income country. Health Policy Plan. 24:151-158. https://doi .org/10.1093/heapol/czn047.

Martin-Collado, D., T. J. Byrne, P. R. Amer, B. F. S. Santos, M. Axford, and J. E. Pryce. 2015. Analyzing the heterogeneity of farmers' preferences for improvements in dairy cow traits using farmer typologies. J. Dairy Sci. 98:4148-4161. https://doi.org/10 $.3168 /$ jds.2014-9194.

Martin-Collado, D., T. J. Byrne, C. Diaz, and P. R. Amer. 2018. Complexity of animal breeding choice making. J. Anim. Breed. Genet. 135:395-409. https://doi.org/10.1111/jbg.12360.

Martin-Collado, D., C. Diaz, A. G. Drucker, M. J. Carabaño, and K. K. Zander. 2014. Determination of non-market values to inform conservation strategies for the threatened Alistana-Sanabresa cattle breed. Animal 8:1373-1381. https://doi.org/10.1017/ S1751731114000676.

McHugh, M. L. 2012. Interrater reliability: The kappa statistic. Biochem. Med. (Zagreb) 22:276-282.

Metzger, M. J., R. G. H. Bunce, R. H. G. Jongman, C. A. Mücher, and J. W. Watkins. 2005. A climatic stratification of the environment of Europe. Glob. Ecol. Biogeogr. 14:549-563. https://doi.org/10 $.1111 /$ j.1466-822X.2005.00190.x.
Meuwissen, M. P. M., P. H. Feindt, A. Spiegel, C. J. A. M. Termeer, E. Mathijs, Y. de Mey, R. Finger, A. Balmann, E. Wauters, J. Urquhart, M. Vigani, K. Zawalińska, H. Herrera, P. Nicholas-Davies, H. Hansson, W. Paas, T. Slijper, I. Coopmans, W. Vroege, A. Ciechomska, F. Accatino, B. Kopainsky, P. M. Poortvliet, J. J. L. Candel, D. Maye, S. Severini, S. Senni, B. Soriano, C. J. Lagerkvist, M. Peneva, C. Gavrilescu, and P. Reidsma. 2019. A framework to assess the resilience of farming systems. Agric. Syst. 176:26-56. https://doi.org/10.1016/j.agsy.2019.102656.

Miglior, F., A. Fleming, F. Malchiodi, L. F. Brito, P. Martin, and C. F. Baes. 2017. A 100-Year Review: Identification and genetic selection of economically important traits in dairy cattle. J. Dairy Sci. 100:10251-10271. https://doi.org/10.3168/jds.2017-12968.

Miglior, F., B. L. Muir, and B. J. Van Doormaal. 2005. Selection indices in Holstein cattle of various countries. J. Dairy Sci. 88:12551263. https://doi.org/10.3168/jds.S0022-0302(05)72792-2.

Nguyen, T. T. T., P. J. Bowman, M. Haile-Mariam, J. E. Pryce, and B. J. Hayes. 2016. Genomic selection for tolerance to heat stress in Australian dairy cattle. J. Dairy Sci. 99:2849-2862. https://doi .org $/ 10.3168 /$ jds.2015-9685.

Nielsen, H. M., P. R. Amer, and T. J. Byrne. 2014. Approaches to formulating practical breeding objectives for animal production systems. Acta Agric. Scand. A Anim. Sci. 64:2-12. https://doi .org/10.1080/09064702.2013.827237.

Nielsen, H. M., P. R. Amer, and I. Olesen. 2008. Challenges of including welfare and environmental concerns in the breeding goal. Pages 24-27 in Proceedings of the European Association of Animal Production, Session 25.1, Abstract No. 2915. EAAP.

Nielsen, H. M., L. G. Christensen, and J. Ødegård. 2006. A method to define breeding goals for sustainable dairy cattle production. J. Dairy Sci. 89:3615-3625. https://doi.org/10.3168/jds.s0022 $-0302(06) 72401-8$.

Nielsen, H. M., I. Olesen, S. Navrud, K. Kolstad, and P. Amer. 2011. How to consider the value of farm animals in breeding goals. a review of current status and future challenges. J. Agric. Environ. Ethics 24:309-330. https://doi.org/10.1007/s10806-010-9264-4.

Oltenacu, P. A., and B. Algers. 2005. Selection for increased production and the welfare of dairy cows: Are new breeding goals needed? Ambio. 34:311-315. https://doi.org/10.1579/0044-7447-34.4.311.

Ooi, E., M. A. Stevenson, D. S. Beggs, P. D. Mansell, J. E. Pryce, A. Murray, and M. F. Pyman. 2021. Herd manager attitudes and intentions regarding the selection of high-fertility EBV sires in Australia. J. Dairy Sci. 104:4375-4389. https://doi.org/10.3168/ jds.2020-18552.

Paakala, E., D. Martín-Collado, A. Mäki-Tanila, and J. Juga. 2020. Farmers' stated selection preferences differ from revealed AI bull selection in Finnish dairy herds. Livest. Sci. 240:104-117. https:// doi.org/10.1016/j.livsci.2020.104117.

Poppe, M., R. F. Veerkamp, M. L. van Pelt, and H. A. Mulder. 2020 Exploration of variance, autocorrelation, and skewness of deviations from lactation curves as resilience indicators for breeding. J. Dairy Sci. 103:1667-1684. https://doi.org/10.3168/jds.2019-17290.

Potoglou, D., P. Burge, T. Flynn, A. Netten, J. Malley, J. Forder, and J. E. Brazier. 2011. Best-worst scaling vs. discrete choice experiments: An empirical comparison using social care data. Soc. Sci Med. 72:1717-1727. https://doi.org/10.1016/j.socscimed.2011.03 .027 .

Pritchard, T., M. Coffey, R. Mrode, and E. Wall. 2013a. Understanding the genetics of survival in dairy cows. J. Dairy Sci. 96:32963309. https://doi.org/10.3168/jds.2012-6219.

Pritchard, T., M. Coffey, R. Mrode, and E. Wall. 2013b. Genetic parameters for production, health, fertility and longevity traits in dairy cows. Animal 7:34-46. https://doi.org/10.1017/ S1751731112001401.

Pryce, J. E., O. Gonzalez-Recio, G. Nieuwhof, W. J. Wales, M. P. Coffey, B. J. Hayes, and M. E. Goddard. 2015. Hot topic: Definition and implementation of a breeding value for feed efficiency in dairy cows. J. Dairy Sci. 98:7340-7350. https://doi.org/10.3168/ jds.2015-9621.

Pryce, J. E., B. L. Harris, J. R. Bryant, and W. Montgomerie. 2009. Do robust cows already exist? Pages $99-112$ in Breeding for Ro- 
bustness in Cattle. M. Klopcic, R. Reents, J. Philipsson, and A. Kuipers, ed. EAAP Publication.

Puillet, L., D. Réale, and N. C. Friggens. 2016. Disentangling the relative roles of resource acquisition and allocation on animal feed efficiency: Insights from a dairy cow model. Genet. Sel. Evol. 48:72. https://doi.org/10.1186/s12711-016-0251-8.

Rauw, W. M., and L. Gomez-Raya. 2015. Genotype by environment interaction and breeding for robustness in livestock. Front. Genet. 6:310. https://doi.org/10.3389/fgene.2015.00310.

Rauw, W. M., E. Kanis, E. N. Noordhuizen-Stassen, and F. J. Grommers. 1998. Undesirable side effects of selection for high production efficiency in farm animals: A review. Livest. Prod. Sci. 56:1533. https://doi.org/10.1016/S0301-6226(98)00147-X.

Sae-Lim, P., H. Komen, A. Kause, J. A. M. van Arendonk, A. J. Barfoot, K. E. Martin, and J. E. Parsons. 2012. Defining desired genetic gains for rainbow trout breeding objective using analytic hierarchy process. J. Anim. Sci. 90:1766-1776. https://doi.org/10 $2527 /$ jas2011-4267.

Sailer, M. O., 2013. crossdes: Construction of Crossover Designs. Accessed Apr. 15, 2020. https://cran.r-project.org/web/packages/ crossdes/crossdes.pdf.

Sawtooth Software Inc. 2008. The MaxDiff System Technical Paper, Technical Paper Series. https://sawtoothsoftware.com/resources/ technical-papers/maxdiff-technical-paper.

Seedorf, J., J. Hartung, M. Schröder, K. H. Linkert, S. Pedersen, H. Takai, J. O. Johnsen, J. H. M. Metz, P. W. G. Groot Koerkamp, G. H. Uenk, V. R. Phillips, M. R. Holden, R. W. Sneath, J. L Short, R. P. White, and C. M. Wathes. 1998. Temperature and moisture conditions in livestock buildings in Northern Europe. J. Agric. Eng. Res. 70:49-57. https://doi.org/10.1006/jaer.1997 .0284 .

Simm, G. 1998. Genetic Improvement of Cattle and Sheep. Farming Press.

Slagboom, M., M. Kargo, D. Edwards, A. C. Sorensen, J. R. Thomasen, L. Hjorto, A. C. Sørensen, J. R. Thomasen, and L. Hjortø. 2016. Organic dairy farmers put more emphasis on production traits than conventional farmers. J. Dairy Sci. 99:9845-9856. https: //doi.org/10.3168/jds.2016-11346.

Strandberg, E., S. Brotherstone, E. Wall, and M. P. Coffey. 2009. Genotype by environment interaction for first-lactation female fertility traits in UK dairy cattle. J. Dairy Sci. 92:3437-3446. https:/ /doi.org/10.3168/jds.2008-1844.

Sy, H. A., M. D. Faminow, G. V. Johnson, and G. Crow. 1997. Estimating the value of cattle characteristics using and ordered Probit model. Am. J. Agric. Econ. 79:463-476.

ten Napel, J., A. A. van der Veen, S. J. Oosting, and P. W. G. G. Koerkamp. 2011. A conceptual approach to design livestock pro- duction systems for robustness to enhance sustainability. Livest. Sci. 139:150-160. https://doi.org/10.1016/j.livsci.2011.03.007.

Thornton, P. K. 2010. Livestock production: Recent trends, future prospects. Philos. Trans. R. Soc. Lond. B Biol. Sci. 365:2853-2867. https://doi.org/10.1098/rstb.2010.0134.

Tixier-Boichard, M., E. Verrier, X. Rognon, and T. Zerjal. 2015. Farm animal genetic and genomic resources from an agroecological perspective. Front. Genet. 6:153. https://doi.org/10.3389/fgene.2015 .00153 .

Vasseur, E. 2017. Animal behavior and well-being symposium: Optimizing outcome measures of welfare in dairy cattle assessment. J. Anim. Sci. 95:1365-1371. https://doi.org/10.2527/jas2016.0880.

Vitali, A., A. Felici, A. M. Lees, G. Giacinti, C. Maresca, U. Bernabucci, J. B. Gaughan, A. Nardone, and N. Lacetera. 2020. Heat load increases the risk of clinical mastitis in dairy cattle. J. Dairy Sci. 103:8378-8387. https://doi.org/10.3168/jds.2019-17748.

Walker, B., C. S. Holling, S. R. Carpenter, and A. Kinzig. 2004. Resilience, adaptability and transformability in social-ecological systems. Ecol. Soc. 9:5. https://doi.org/10.1103/PhysRevLett.95 .258101 .

Wall, E., G. Simm, and D. Moran. 2010a. Developing breeding schemes to assist mitigation of greenhouse gas emissions. Animal 4:366-376. https://doi.org/10.1017/S175173110999070X.

Wall, E., A. Wreford, K. Topp, and D. Moran. 2010b. Biological and economic consequences heat stress due to a changing climate on UK livestock. Adv. Anim. Biosci. 1:53. https://doi.org/10.1017/ S2040470010001962.

Yoo, H. I. 2020. lclogit2: An enhanced command to fit latent class conditional logit models. Stata J. 20:405-425. https://doi.org/10 $.1177 / 1536867$ X20931003.

Zhou, M., W. M. Thayer, and J. F. P. Bridges. 2018. Using latent class analysis to model preference heterogeneity in Health: A systematic review. PharmacoEconomics 36:175-187. https://doi.org/10.1007/ s40273-017-0575-4.

\section{ORCIDS}

J. G. Burns ํㅏㄴ https://orcid.org/0000-0003-4617-7453

K. Glenk (i) https://orcid.org/0000-0002-2472-0235

V. Eory (i) https://orcid.org/0000-0002-7134-3233

G. Simm @ https://orcid.org/0000-0002-4801-903X

E. Wall (1) https://orcid.org/0000-0002-7072-5758 